\section{CARBOLIC ACID AS AN ANTISEPTIC AND DISINFECTANT.}

WITH A FEW CASES ILLUSTRATIVE OF ITS BENEFICIAL EFFECTS IN CATARRHAL, ASTHMATIC, AND BRONCHIAL AFFECTIONS.

Bx ANGUS MACKINTOSH, M.D. (Continued from p. 400.)

THE following cases will appear interesting to the profession in so far as they illustrate the beneficial effects of carbolic acid in complicated and chronic diseases, and prove that, by minute care and constant application, the desired result may be occasionally accomplished, however adverse circumstances may appear.

The first case is that of a young girl who had lupus of the nose of ten or eleven years' standing, and who, after trying all the hospitals and dispensaries in the west of England, and some in the neighbourhood of London, entirely relinquished the hope of ever getting better; but, through the means adopted, her nose and the adjacent parts, that were extensively destroyed, have been restored. Two years have elapsed since she was considered cured, and there is not the slightest symptom of the disease returning. The second case is that of a married woman, the mother of several children, in whom over-straining in lifting heavy weights caused strangulated inguinal hernia, and who, without an operation, has made a complete recovery. Relative to this case I consulted the late Professor Syme of Edinburgh, and Sir Wm. Fergusson of London. To both of these gentlemen I owe a lasting debt of gratitude for many wise suggestions on various occasions. The third case is that of a middleaged man, who, in a drunken squabble, sustained a compound dislocation of the ankle and compound comminuted fracture of the fibula. This man also has made a rapid recovery, and was in course of a few months able to work at his trade, and to walk surprisingly long distances apparently without any great inconvenience.

Case 2.-The following is the history as given by the mother up to the end of October, 1867, when my attention was called to the case:-H. E-, aged seventeen years, suffered from 1855 to 1858 considerably from inflamed and swollen eyes; constitution always rather delicate. About the end of 1858 her eyes got gradually better, but shortly thereafter she complained of her nose, at the tip of which one or two red spots appeared; these in course of time broke up, forming a scab, and ever since the disease has been extending. After treatment at several public institutions, as already stated, the case was considered hopeless and incurable.

On examination I found her of scrofulous diathesis, figure slender and delicate, and suffering from a catarrhal affection with sore-throat. The nose up to the bridge was swollen and inflamed, exhibiting here and there dull-red points; the tip covered with scab, and underneath the scab small ulcers. The cartilages and some of the nasal bones were partly destroyed, and the adjacent soft parts to a much greater extent. The lips were slightly enlarged; the nostrils almost closed with tumefaction; the eyelids swollen, inflamed, and everted. I informed the mother of the difficulties to be overcome in attempting to bring about a cure, and said that if any means could possibly do good, it must be through a long and tedious process, to which she replied that no process could be too tedious if it were only effectual.

About this time Dr. James Dewar's (of Kirkcaldy) sulphurous acid theories were creating some sensation on the north side of the Tweed, and I considered this a favourable opportunity for trying it, as, from a pamphlet sent me by a friend, it appeared to be particularly suitable to skin complaints. The parents of the patient lived close to the back of my establishment, where I might conveniently visit her twice a day. I ordered a quantity of sulphurous acid from a distance, being not kept by any chemist in the town, and instructed the mother to get an apartment ready, where she might keep her daughter undisturbed for at least two months, which she promptly prepared, the daughter herself being willing to submit to any line of treatment. The place selected was a bedroom about $10 \mathrm{ft}$. square, where the girl was to sleep by night and live by day.

On Nor. 1st I commenced the application of the sulphurous acid to the nose. I visited my patient twice a day, and applied the acid myself at each visit; the mother, in my absence, dressed it twice more during the day, according to directions-in all, four times in twenty-four hours. The room also was fumigated regularly night and molning: by burning sulphur, the doors being closed. She had plenty of beef-tea, mutton-broth, porter and milk, but refused codliver oil, on the ground that she took it for years without any benefit, and that latterly it invariably induced relaxation of the bowels. Internally I prescribed the following mixture, which was continued throughout with the erception of two or three short intervals, when the stomach got a little disordered: Liquor arsenicalis, one drachm; tincture of calumba, six drachms; clove water, three ounces; syrup of orange, two ounces; water, three ounces; of which a dessert-spoonful was to be taken every six hours, between meals. This treatment was continued without intermission for two months, but without apparent change in the desired direction. No unusual symptom supervened; slight functional derangement of the stomach and bowels occurred on two or three occasions, but not to any unmanageable extent. The application of the acid did not cause any pain or troublesome irritation; it was described as agreeable and rather soothing. I may add that my patient got quite heartless at this result; but I encouraged her by saying that there was one other remedy I should like to try, in which I had great faith.

About the beginning of January, 1868, I changed the sulphurous acid for carbolic acid, and discontinued burning the sulphur. I desired the nose to be poulticed for two nights in succession, which removed portions of the scab; I then mixed the carbolic acid and linseed oil in equal proportions, and ordered the nose to be thoroughly painted with the lotion once every six hours, which was done by means of a camel's-hair brush. The odour was rather disagreeable at first, but did not affect the breathing so much as one would imagine. In a corner of the room a quantity of the acid was constaintly kept on a plate, to charge the air, and the same mixture as before administered internally. In the course of a week my patient began to complain of great irritation in and about the diseased part of the nose, so much so that I had recourse to poultices. I next applied carbolic-acid putty, but she could not endure the pressure; I therefore returned to the lotion, of the same strength as before, and continued it without any disagreeable or painful symptom arising. It seemed as if the crisis was passed. In a month's time from the commencement of the carbolicacid treatment, the catarn from which she suffered had given way, the throat was easier, and the expectoration less; very little pus could be detected, and the scab was nearly all gone; in short, a general improvement could be seen externally, which gave a new stimulus of encouragement to all concerned. From this period the treatment was attended to with greater care and regularity. About the end of the second month the scab had disappeared, as well as the pus, and the lotion was subsequently used only three times a day. From this date to the end of the sixth month the case went on improving, when a complete cure was effected.

I have not the remotest doubt that the carbolic acid was the direct means by which the cure was accomplished in this long-standing and obstinate case, combined perhaps with a little beneficial aid from the arsenic mixture. On its modus operandi I have not been able to decide.

QUERY.-Has the carbolic acid brought about this desired effect by first clestroying the putrefactive organisms of the atmosphere which are supposed to favour if not to create pus, and hence the cure; or has it diminished the quantity of pus by giving increased tone of vitality to the parts through its stimulating and chemical effects, and thus prevent the tendency in the parts to disorganisation and putrefaction?

CAse 3.-On May 18th, 1869, I was called to see a married woman, M. G-, aged forty-two, who had inguinal hernia of the right side, which I managed to reduce by taxis. On the 25th $I$ was again summoned in haste, as, in consequence of some violent exertion, she had had a return of her complaint. On examination I found a considerable tumour in the right groin, rather painful when manipulated, which I concluded to be inguinal hernia, and feared, from the sym. 
ptoms, to be strangulated. Taxis with cold applications haring been tried without success, I administered chloroform and endeavoured to effect reduction, but failed. The patient was strong and healthy. I gave an enema of warm Tater and turpentine, after which she was very sick. I again tried, but unsuccessfnlly, to reduce the tumour, which now became red, tense, and painful to the touch. Every effort having been frustrated, I was necessitated to propose an operation. The patient, however, positively declined to submit to any interference of that kind, and said she would rather die than undergo an operation; and this resolution she adhered to in spite of advice and persuasion on the part of myself and her friends.

Tay 26th.-Tumour red, tense, and painful; no motion of the bowels; sick and urging. Another enema of gruel, turpentine, and laudanum was given; brandy-and-water internally.

27th.-Stercoraceous vomiting; pulse small and feeble; tumour painful and slightly discoloured. Warm poultice to tumour; brandy-and-water, milk-and-water, and beef-tea at intervals internally. No motion of bowels; enema given.

28th.-Vomiting continues; countenance pale and anxious; extremities cold; pulse small; mortification in tumour; no motion of bowels. Hot poultices to tumour, renewed every two hours. Can take nothing except brandy-and-water and milk. Enema given.

29th.-Tumour broke open during the night, forming an abnormal anus; large quantity of fæcal matter discharged. Patient not so distressed; pulse small and feeble; face pale and covered with cold perspiration; urging and vomiting almost ceased; gangrene spreading; no motion of bowels. Nitrate of silver freely applied outside the gangrenous part; poultice, saturated with carbolic acid, to wound. Brandy, milk, and beef-tea internally; hot jars to feet.

30th.-Sickness and urging returned; pulse weak and feeble; perspiration profuse; extremities cold. No motion of bowels; contents discharged freely through the preternatural anus when patient turns on the right side. Mortification extending rapidly. Brandy and soda-water, milk and lime-water given at short intervals. Nitric acid applied to the edges of the wound, followed by a stream of cold water; feet kept warm; carbolic acid poultice to wound; enema twice a day; opiate at night.

31st. - Sickness better; mortification checked; pulse somewhat stronger. Slept for a few hours, and took a little beef-tea during the night. Nitric acid again applied; wound dressed as before. No motion of bowels; enema twice a day.

June 1st.-Patient slightly better; took a quantity of lime-water and milk. Not so much discharge from wound. Slept several hours. Beef-tea and brandy to be continued; nitrate of silver to wound; poultice as before. No motion of bowels. Fnema twice a day ; opiate at night.

2nd.-Sickness but slight; pulse stronger; took more beef-tea and brandy. Slept for four hours. No motion of bowels. Enema at night.

3rd.-From this time the patient continued to improve, and for six weeks the motions passed regularly through the abnormal anus several times in the day. No wind nor anything else passed through the rectum for that period. As she began to get stronger, the thigh of the right side was flexed on the abdomen, the knee at right angles, and fixed in that position, from which she was not to move except to relieve the bowels, which she could only do by turning slightly on her right side. The edges of the wound were partially drawn together by means of adhesive plasternitrate of silver being used more or less every day, -and dressed with carbolic acid and oil in equal proportions.

Being surprised and puzzled that no evacuation of any kind passed through the natural channel per rectum, I ventured to explore the bowels through the inguinal opening with a small-sized bougie, which I could easily pass, without any pain, for about four inches, in the direction of the symphysis pubis, but in no other; from which I concluded that a collapse of the bowels must have taken place, followed by adhesions. At my next visit I used an exploring needle, and managed to pass it, with a little gentle force, in the desired direction, though not without considerable pain to the patient. Having introduced the needle, I endeavoured to dilate the parts, and succeeded so far as to be able to follow the course of the needle with the bougie, which I left in the bowel all day and night. Next morning I was informed that wind and a small quantity of slimy fæces passed per rectum. I replaced the first bougie by a larger one, which was also left in the bowel for twenty-four hours. On withdrawing it, an enema of warm water and turpentine was given; and the wound was dressed with the carbolicacid lotion. At my next visit $I$ was told that the patient had had a copious evacuation per rectum, without any pain. From this time the contents of the bowels regularly passed through the natural channel, and the wound gradually healed, till, in the course of five months, it completely closed, leaving no pain, nor any abnormality, with the exception of a little contraction of the skin.

Carbolic acid in this case proved of the greatest value as a disinfectant. Being the middle of summer, the heat was so intense that the effuvium and exhalations from the discharges, \&c., contaminated and infected the atmosphere in the house to such an extent as to be altogether unbearable, and quite sufficient to create and propagate disease; but the acid, being freely used, charged every thing and every place with itself, so as to render the surrounding medium capable of being breathed with impunity. During the five months the wound was in closing, scarcely any pus was seen : so much for the acid, whether in confirmation of the chemical or the germ theory.

The bowels were, I believe, in such a condition, owing to the collapse and consequent adhesions, that their contents could never again have been directed per rectum by any effort of nature. It shows how much good may be secured by timely interference, and how careful we should be in studying every symptom to bring our case to a happy issue.

(To be continued.)

\section{g a dititot}

\section{OF THE PRACTICE OF}

\section{MEDICINE AND SURGERY IN THE}

\section{HOSPITALS OF LONDON.}

Nulla autem est alia pro certo noscendi via, nisi quamplurimas et morborum et dissectionum historias, tum aliorum, tum proprias collectas habere, et
inter se comparare.-Monga

\section{ST. GEORGE'S HOSPITAL.}

OPERATIONS BY MR. PRESCOTT HEWETT; CLINICAL REMARKS.

Excision of a bleeding Novrus.-The patient, a girl eight years of age and of very exsanguine appearance, presented a small bleeding tumour on the outer side of the lower third of the thigh. After its removal, $\mathrm{Mr}$. Hewett gave an account of its history and nature, and the course he had adopted for its extirpation. He said that a more interesting case could scarcely have been brought before the notice of the class. Four years previously, on the growth being first noticed as a small, movable, soft lump, of bluish tint, the patient was taken to the Devon County Hospital, and seen by the surgical staff in consultation with Mr. Square. Its characters at that time being such as to lead to the opinion that it was malignant, it was decided that, if confirmatory evidence was obtained by the introduction of a needle, amputation should be performed. This proceeding, however, only established its vascular nature, and interference was for the time postponed.

The puncture had healed and a year elapsed, when the lower part of the lump gave way, and there ensued an oozing of blood, which had continued up to that day, in spite of an attempt by $\mathbf{M r}$. Square to arrest it by the injection of tannic acid. At the earnest request of her parents and friends, the child had recently been placed under his (Mr. Hewett's) care, and he had now only done what had been proposed as the next step by the surgeon under whose care the patient had formerly been: with a view to deciding what course should be finally adopted, he had freely exposed the growth by an incision through the integument. Before doing so it had been obvious that the growth could 